\title{
Medulloblastoma with myogenic differentiation: a rare medulloblastoma variant in a young child
}

\author{
John Ross Crawford, ${ }^{1}$ Michael L Levy ${ }^{2}$
}

'Department of Neurosciences and Pediatrics, University of California San Diego, San Diego, California, USA

${ }^{2}$ Department of Neurosurgery, University of California San Diego, San Diego, California, USA

Correspondence to Dr John Ross Crawford, jrcrawford@ucsd.edu

Accepted 9 August 2015
CrossMark

To cite: Crawford JR, Levy ML. BMJ Case Rep Published online: [please include Day Month Year] doi:10.1136/bcr-2015212322

\section{DESCRIPTION}

A 3-year-old girl presented with a 3-week history of headaches, unsteady gait and episodic vomiting. On neurological examination, she had gaze-evoked nystagmus, intermittent titubation and mild ataxic gait. MRI revealed a large posterior fossa tumour with reduced diffusivity and heterogeneous nodularappearing enhancement (figure 1). MRI of the spine and subsequent cerebrospinal fluid analysis were negative for disseminated disease. Following gross total resection, pathology demonstrated a malignant small blue cell neoplasm with anaplasia, nuclear pleomorphism and myxoid areas containing eosinophilic cells (figure 2). Immunohistochemistry (IHC) for myogenin revealed nuclear positivity in the myxoid areas consistent with a diagnosis of medullomyoblastoma. IHC revealed no loss of expression of INI-1, excluding a diagnosis of atypical teratoid rhabdoid tumour. Fluorescence in situ hybridisation for n-MYC amplification was negative. However, amplification of c-MYC was observed in almost $20 \%$ of cells, which showed amplification of chromosome 8 using centromeric probes.

The patient underwent craniospinal proton beam radiation therapy with adjuvant chemotherapy and remains in remission at 1 year postdiagnosis.

Medulloblastoma with myogenic differentiation, also sometimes referred to as medullomyoblastoma, is an extremely rare variant of medulloblastoma, characterised by neuroectodermal small blue cell tissue and rhabdomyoblastic tissue, which is confirmed by positive myogenin immunostaining and no loss of INI expression to exclude atypical

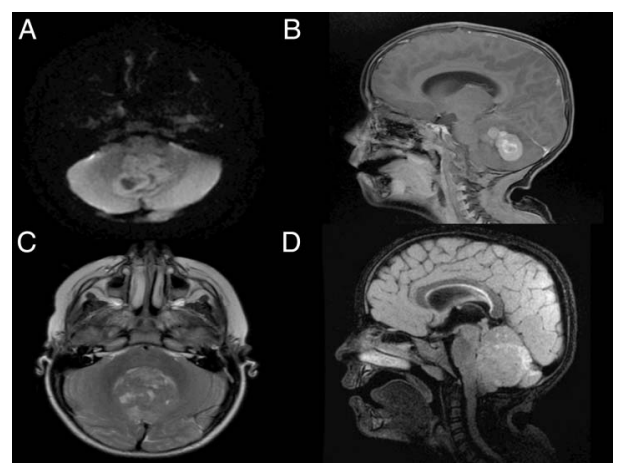

Figure 1 Neuroimaging features of medulloblastoma with myogenic differentiation. Diffusion-weighted MRI sequence reveals a fourth ventricular neoplasm with reduced diffusivity $(A)$. The tumour has a nodular appearance on postgadolinium (B) and T2-weighted sequences (C), with associated mass effect and early hydrocephalus (D).

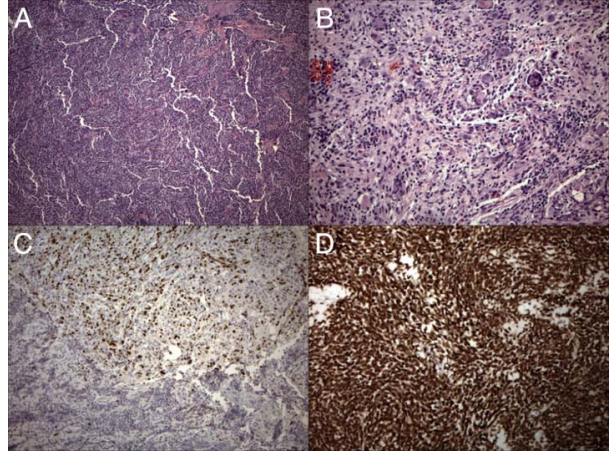

Figure 2 Neuropathological features of medulloblastoma with myogenic differentiation. Pathology reveals a malignant small blue cell tumour with high nuclear to cytoplasmic ratios, hyperchromatic nuclei and scattered intermixed multinucleated giant cells (A and B). Immunostaining with myogenin revealed nuclear positivity in the myxoid areas with no significant staining of small blue cells (C) and absence of INI-1 staining, excluding a diagnosis of atypical teratoid rhabdoid tumour (D).

teratoid rhabdoid tumour. Neuroimaging may demonstrate biphasic nodularity, corresponding pathologically to the different tissue types present within the neoplasm, which may differentiate medullomyoblastoma from classic medulloblastoma. ${ }^{1}$ The presence of anaplastic features is associated with worse prognosis. ${ }^{2}$ The molecular features of medullomyoblastoma are distinct from the four common

\section{Learning points}

- Medulloblastoma with myogenic differentiation, sometimes referred to as medullomyoblastoma, is a very rare medulloblastoma variant; it may have a nodular appearance on postgadolinium MRI sequences, mimicking nodular desmoplastic medulloblastoma or atypical teratoid rhabdoid tumour.

- Medulloblastoma with myogenic differentiation does not fall into the current conventional molecular stratification schema of medulloblastoma and therefore far less is known about ideal management and long-term prognosis.

- The amplification of c-MYC through polyploidy/ hyperdiploid chromosome 8 complement is a novel form of non-focal amplification and worthy of further study in larger cohorts of similar tumours. 


\section{Images in...}

stratifications reported in medulloblastoma (wingless, sonic hedgehog, group 3 , group 4 ), ${ }^{3}$ adding further complexity to this extremely rare paediatric brain tumour.

Competing interests None declared.

Patient consent Obtained.

Provenance and peer review Not commissioned; externally peer reviewed.

\section{REFERENCES}

1 Leonard JR, Cai DX, Rivet DJ, et al. Large cell/anaplastic medulloblastomas and medullomyoblastomas: clinicopathological and genetic features. J Neurosurg 2001;95:82-8.

2 Helton KJ, Fouladi M, Boop FA, et al. Medullomyoblastoma: a radiographic and clinicopathologic analysis of six cases and review of the literature. Cancer 2004;101:1445-54.

3 Taylor MD, Northcott PA, Korshunov A, et al. Molecular subgroups of medulloblastoma: the current consensus. Acta Neuropathol 2012;123:465-72.

Copyright 2015 BMJ Publishing Group. All rights reserved. For permission to reuse any of this content visit

http://group.bmj.com/group/rights-licensing/permissions.

BMJ Case Report Fellows may re-use this article for personal use and teaching without any further permission.

Become a Fellow of BMJ Case Reports today and you can:

- Submit as many cases as you like

- Enjoy fast sympathetic peer review and rapid publication of accepted articles

- Access all the published articles

- Re-use any of the published material for personal use and teaching without further permission

For information on Institutional Fellowships contact consortiasales@bmjgroup.com

Visit casereports.bmj.com for more articles like this and to become a Fellow 